\title{
Replies to Timmerman and Gorman
}

\author{
John Martin Fischer ${ }^{1}$
}

Received: 7 June 2021 / Accepted: 7 January 2022 / Published online: 31 January 2022

(C) The Author(s) 2022

\begin{abstract}
In my reply to the thoughtful comments of Timmerman and Gorman, I take up, and further explore, some main questions, including: Can a horribly immoral person (a moral monster) lead a meaningful life? Similarly, can a significantly deluded person lead a meaningful life? What role do judgments of meaningfulness play in our normative framework? How can we understand the debate between those who would embrace the possibility of immortality and those who would reject it? What is the role of narrativity in evaluating meaning in human lives, and how would this concept apply to immortal lives? If death can be a bad thing for the deceased, should we fear death (the status of being dead)?
\end{abstract}

Keywords Death · Experience machine $\cdot$ Harm · Immortality $\cdot$ Lucretian mirror image argument $\cdot$ Meaning in life $\cdot$ Narrative

I wish to begin by thanking both Travis Timmerman and August Gorman for their extremely insightful and generous contributions. An author couldn't ever expect more thoughtful or kind engagement with their work, and I am immensely grateful. I have already adjusted views in light of their cogent critiques, and I will continue to reflect in ways prompted by their comments. In some instances I know that I have fallen short of successfully addressing their worries, but in my replies at least I display my agreement with Franz Kafka: "When you are up against the wall, start describing the wall."

John Martin Fischer

john.fischer@ucr.edu

1 Department of Philosophy, University of California, 92521 Riverside, CA, USA 


\section{Reply to Timmerman}

\section{Can Immoral Lives Be Meaningful?}

This is a good and difficult question. Timmerman points out that having a positive impact on someone else's life is often thought to enhance meaning in one's life, and he wonders why having a negative impact would not detract. I'm not confident that our grasp of the distinctive value of meaningfulness in life is firm enough, or detailed enough, to answer this question, but seeking to answer it may help to sharpen our understanding of this value, which is typically taken to be analytically distinct from morality and happiness.

There is an important ambiguity in the notion of meaningfulness - one that can lead to talking past each other (here and more broadly in the literature on meaning in life). Consider: "Standing up for her rights sends a very meaningful message," "His sincere apology is a meaningful act on his part," "I found that story of redemption very meaningful," and so forth. Here "meaningful" expresses a positive normativeand, in particular, ethical-judgment; call it the positive sense of "meaningful."

Now contrast: "The rings on the tree have a certain meaning. They are meaningful in regard to the tree's age," "That is not just a random event. It is meaningful-it is an important clue to solving the mystery," "The rise in average temperatures throughout the globe is not trivial; it is definitely meaningful," and so forth. Here the term, "meaningful," does not convey a positive ethical evaluation; call it the "neutral" sense. Whereas some, perhaps including Timmerman, employ the term in its positive sense, I use it in the neutral sense. We are thus philosophical ships passing in the dialectical night. I hold that both senses are genuine and legitimate, however, and so neither of us is on an analytic Titanic.

This mismatch might explain the apparent disagreement about the notion that Hitler's life should be considered meaningful, although morally monstrous. The life is clearly not meaningful in the positive sense. It is however more complicated to figure out whether it is properly deemed a meaningful life in the neutral sense. Here I can see two reasonable points of view. On one approach (that presumably would be accepted by Timmerman, even given the neutral usage), the objective element of meaningfulness is not present, since Hitler's life cannot be recognized as valuable from an "external" perspective. After all, being the mastermind of a genocide doesn't commend itself to reasonable observers. No disagreement from me on this, and on this way of thinking about the objective component (call it the "particularist way"), Timmerman is correct.

If we think of the projects and activities in all their florid and hideous particularity, they cannot be deemed objectively worthwhile. Consider now a different way of interpreting the objective component of the neutral sense of meaningfulness. Here is where things get particularly delicate. If we consider Hitler's life in an "abstract" way, the situation is different. Bracketing the particular implementations of the projects, they would appear to constitute a paradigm of a life that would pass the test of objectivity. Many of the factors typically invoked as meaningfulness-enhancing are present: connecting with something larger than oneself, making a mark on the world, working together with colleagues in ongoing projects that require close coordination 
and teamwork, loving other people (Eva Braun?) or at least ideals (presumably in the specific form of the Vaterland and its superior Aryan race), and so forth. Considered abstractly, the projects would apparently pass the objective value test.

I have generally adopted the neutral sense of meaningfulness, with the more abstract characterization of projects. On this view, Hitler's life was meaningful. Perhaps Timmerman and others employ "meaningfulness" in its positive sense, or adopt the neutral sense paired with the particularist way of conceiving of the projects. On either of these options, Hitler's life would not be deemed meaningful.

I do not know how to resolve this disagreement (or to argue that one way of conceptualizing meaning in life is to be preferred to the other). It is an empirical fact that people use "meaningful" in the two senses identified above. Perhaps the ships can both end up in lovely locations. I do however think that it is important to have a way to mark human lives (and deaths) as importantly different from those of nonhuman animals, and to allow that there is a pro tanto reason-giving value apart from happiness and morality - a value possessed even by persons who do not live admirable lives (all-things-considered). Even the neutral sense of "meaningful" gives rise to a reason for choice and action; it is however not an ethical reason for action.

\section{The Constraints of Connection with Reality and Free Will}

One might employ Robert Nozick's famous example of the "experience machine" (Nozick 1974) to motivate both basic requirements I posit for having a meaningful life: not being deluded about important aspects of one's life and being capable of acting freely (i.e., not being a mere puppet or plaything of another or even nature). Note that I do not interpret the latter requirement as entailing libertarianism about freedom and causal determinism; being a mere puppet or plaything, even of nature, does not follow from causal determinism - but that is, of course, another story. If you are involuntarily hooked up to the experience machine forever, you are neither connected with external reality in the right way (a knowledge-conferring way), nor capable of acting freely. You may believe that you have knowledge of external reality, and that you are free, but these beliefs are not true.

Now Timmerman invites us to consider these two cases (versions of the same initial set-up):

Two experience machines: Imagine two people each living their life in a sort of experience machine where everyone they have the experience of interacting with is just part of a computer program. Consequently, their (in)actions can have no effect on anyone's well-being.

Now, the first person lives the life of Susan Wolf's The Blob in the machine. They watch bad sitcoms on a loop, only eating cheap pizza and drinking cheap beer for every meal, and never do anything else.

The second person, however, lives what would be a paradigmatically meaningful life, except for the fact that they're in an experience machine. Suppose, relative to their evidence, they end apartheid, discover cures for all types of cancer, create the most beautiful art in the world, and make significant discoveries in logic, philosophy, and mathematics. 
I interpret the examples as involving no connection between the people and external reality in the way it is presented to them. That is, they are not just isolated from other people, but from essentially everything external. This is the way in which Nozick originally thought of his famous experience machine example and the way in which I am interpreting it. One might imagine a different version of Timmerman's examples in which the persons are only isolated from other people, but not from external reality in general. This would raise the question of how much delusion is required for a meaningful life; after all, we are wrong about a lot in our lives. My approach would be to maintain that there are cases on both sides of the line, and where there is not too much delusion, a life can be meaningful.

Timmerman points out correctly that on my view, neither life is meaningful (where the examples are interpreted as involving total delusion). He finds this implication implausible, as he thinks that the second person's life is at least arguably meaningful (if not maximally so). He focuses first on the not-being-deluded constraint, and he contends that it is plausible that the second person's life is overall meaningful insofar as the meaningfulness-enhancing features outweigh the meaningfulness-diminishing total delusion.

I feel pretty confident that neither life is at all meaningful. I am inclined to think that a life that is systematically deluded cannot rise to the threshold of meaningfulness. As Nozick puts it, if he were to find out that he had always been hooked up to an experience machine, he would conclude that he had been living a lie. He also writes that he would not choose to have his child live such a life or welcome discovering that his child does.

I agree with Nozick, but it is hard to prove this point (or, for that matter, to disprove it). I am convinced by Nozick's experience machine example and Nagel's example of being betrayed behind one's back, of various examples of clandestine violations of one's privacy, and many others, that you can be harmed, or that an evil can befall you, even if you are blissfully ignorant (and not otherwise affected). I agree with the general point that morality and ethical value are not solely matters of experiences (or reducible to experiences). We are here concerned not primarily with ethics and morality, but meaningfulness. Although they are analytically distinct (when "meaningful" is interpreted neutrally), it is however natural to suppose they are similar in central respects.

Consider a very significantly psychotic individual confined to a mental institution. He sincerely believes he is Napoleon, and, accordingly, has a rich and rewarding internal life. As with all of us, there are experiential ups and downs, but still it would seem that, from the inside, the life scores high on the meaningfulness scale. We might even say that his life is "meaningful to him" or "subjectively meaningful." Does he lead an objectively meaningful life? I don't think so. I believe that his extreme mental illness and psychosis preclude this. We might think otherwise if we do not keep in mind the differences between subjective meaningfulness (meaningful to an individual, from her point of view) and objective meaningfulness (meaningful for that individual, from an objective or perhaps interpersonal point of view). Of course, the "would-be Napolean" does have moral standing and certain rights, even though (on my view) he does not meet the minimal threshold for living a meaningful life.

But these matters are not so simple. David Chalmers writes: 
The year is 2095. Earth's surface is a wreck - a casualty of nuclear warfare and of climate change. You could live a hardscrabble existence here, avoiding gangs and dodging mines, with your main aspiration being survival. Or you could lock your physical body in a well- protected warehouse and enter a virtual world. Let's call this virtual world the reality machine. In the reality machine, you'll be much more comfortable than in physical reality. This world is much safer, and there's plenty of pristine territory for everyone. Most of your friends and family are there already. There are plenty of opportunities to build a community and make a difference.

You face a choice. Will you enter the reality machine?

You may well say no: the reality machine is simply an escapist fantasy. Life in a virtual world doesn't mean anything; at best, it's like spending one's life at the movies or playing video games. You should stay in the physical world where you can have real experiences and where you might be able to make a real difference.

Or you may say yes. The reality machine is on a par with the physical world. You can live a meaningful life there just as you did in the physical world. In the circumstances, it will be a far better life.

These answers reflect two different answers to the Value Question: Could you live a good life in virtual reality?

My answer to the Value Question is yes. In principle, life in virtual reality can have the same sort of value as life in nonvirtual reality. (Chalmers 2022 [forthcoming]: 311)

Chalmers goes on to compare the reality machine with Nozick's experience machine. He offers a critique of Nozick's (and my) view that the agents in question do not live meaningful lives. He also considers a hypothesis that he and other philosophers take to be a genuine possibility: that we are all in a huge simulation. Just as with the examples of the experience machine and reality machine, he holds that we could lead good and meaningful lives, even if we were mere "information" in a simulation.

Chalmers's ingenious defenses of positive answers to the "value question" in these hypothetical examples offer reason to take Timmerman's contention about a deluded but "accomplished" individual seriously. They point to the difficulty of establishing the Nozickean analysis of these cases, and, as I wrote above, I cannot prove that we should accept a negative answer to the value question.

A careful exploration of these issues is (fortunately!) beyond the scope of this paper, but I'll mark a few thoughts for further evaluation. Note that in the example of the reality machine, you are not deluded throughout your life, and you make what is presumably a free choice to enter the machine. I take it then that your life overall could be meaningful. Perhaps the period after you enter the machine (the "after"life, so to speak) would not generate meaningfulness-enhancing (or detracting) features, but your life overall could still be meaningful. Same with a parallel experience machine example.

The examples offered by Timmerman are importantly different: the individual in question is presumed (at least so far as I can tell) to have been deluded all along. Here I would maintain that the individual's life is not meaningful. This is simply an 
assertion here and does not address the arguments about what constitutes a "good" life by Chalmers, but at the very least it indicates a noteworthy difference in cases: "all-along" versus "after-choice" delusion cases. One might conflate them and inappropriately import intuitions about the after-choice cases to the all-along-cases.

It is unclear however what role freely choosing the experience-machine or realitymachine plays in underwriting overall meaning in life. There could be different kinds of psychotics. Some of them have been significantly deluded all along, and I believe that they are incapable of leading meaningful lives. (I assume here that the mental illness is so extreme that his beliefs about the world are almost all false.) What about someone who develops this sort of psychosis as an adolescent or adult? Such an individual would not have freely chosen his psychosis, but nevertheless I believe he could lead a meaningful life overall. What seems to be crucial is that there be a (significant) period of contact with reality; even if this is followed by substantial delusion, the life overall can be meaningful.

What if we are all in a simulation created by a bored adolescent on Exoplanet Alpha? This would be an all-along delusion case, and my intuition is that we would not be leading meaningful lives (although one's intuitions about such wild scenarios are not worth much). What if Alpha is a simulation created by such an adolescent on Beta, and Beta is in turn a simulation created by an adolescent on Gamma, and so on "all the way back"? This is particularly difficult, and I won't venture a guess about the possibility of meaningfulness on Earth or in such a universe in general. Your guess would be as good as mine.

Let's move on to the constraint requiring the capacity to act freely (at some important points in one's life, if not all). Timmerman asks us to consider the following two cases of persons who are both assumed to be unfree:

The Blob Puppet and the Accomplished Puppet: Again, the first person lives the life of Susan Wolf's The Blob. They watch bad sitcoms on a loop, only eating cheap pizza and drinking cheap beer for every meal, and never do anything else. The second person lives what would be a paradigmatically meaningful life, except for the fact that they lack free will. Nevertheless, they do form desires to pursue all sorts of welfare-enhancing goods, and intellectual pursuits, and they act on such desires. They develop into the type of person that does such things as curing all types of cancer, and ending apartheid. They see and appreciate beautiful works of art and learn deep truths about logic, philosophy, and mathematics.

As with the non-delusion constraint, Timmerman is not convinced by my contention that both lives utterly lack meaningfulness. I claimed in the book that the lack of meaning in the life of the individual hooked into the experience machine is overdetermined by failure to meet the two constraints (non-delusion and freedom). Timmerman's pair of examples here usefully homes in on the freedom requirement. I hold that both persons lead lives that are not at all meaningful. Who would aspire to the life of a marionette, or wish it for one's children?

Recall that our lives correspond to narratives, and I suggest that we can fruitfully think of the meanings of our individual lives as the contents of our narratives. The three requirements for a narrative are: affective engagement, meaning holism, and an 
ending. Now what is particularly relevant here is meaning-holism. Upon reflection, I do not believe that creatures who are incapable of acting freely can write stories that have meaning holism, whereas we-free creatures - can.

Periods of conscientious and hard work toward a goal can be vindicated and given more positive value by subsequent success in reaching the goal. Years of study and preparation are given more value by subsequent acceptance to medical school, whereas such efforts may be endowed with less value by subsequent failure to be accepted. A hiring decision can be vindicated by the subsequent excellence of the employee, whereas the decision can be shown to have been a mistake (or perhaps a poor choice) by subsequent poor performance. A long period of suffering in a relationship is given more positive value by later success that builds on the lessons learned during the time of struggle. Such a period could however be a "dead-weight loss," if later success is a lucky accident not related to the previous suffering. There are myriad examples of meaning holism in our lives - meaning that derives from the relationships between the parts of our lives. I borrow some of these examples from seminal work by David Velleman. (Velleman 1991)

In contrast, I cannot think of any examples of non-human animals, the stories of whose lives contain meaning holism. If a dog attends "obedience school" and later behaves according to its master's wishes, this behavior does not enhance the value (for the dog) of the time of training. I think that there is value in a dog's life, but not narrative value. Perhaps the later obedience vindicates the master's past decision to take the dog to the trainer, but it does not retroactively bestow greater value on the time in obedience school for the dog.

I do not think it would be any different if a human being were secretly manipulated (or similarly causally influenced) in such a way as never to act freely. If an individual is thoroughly manipulated-perhaps via clandestine electronic stimulation of their brain by a "nefarious neurosurgeon" who needs colleagues(!) into studying to get into medical school, I do not think that subsequent success (or failure) retroactively bestows positive (or negative) value on these efforts. Similarly, if an individual so manipulated learns from their prior struggles and subsequently has a happier marriage, this does not bestow additional value on the time of struggles. And so forth.

I do not have an argument that acting freely is required for meaning holism, and I acknowledge that this constitutes a gap in my argument. I appeal however to intuitions about cases, and I cannot think of a case in which there would be meaningholism in an animal's life or that of a thoroughly manipulated human being. The issue may however hang on how we interpret "meaning-holism," or what specific sort of meaning-holism we have in mind. For example, when an individual manipulated into attending medical school subsequently is admitted, this does not bestow value on her prior efforts by showing that they reflect well on her. Similarly, a manipulated choice that is vindicated later is not thereby endowed with value that is attributable to the agent for making a good choice.

In contexts of manipulation, then, certain important dimensions of value and meaning are not retroactively affected (or fixed) by subsequent events. I am here assuming that the manipulation in question is consistent with the person's genuinely acting. If not, it is straightforward that the life is not meaningful. 
So life's having a meaning — a narrative content—entails freedom, a freedom absent in the case of involuntary connection to an experience machine. We can now construct a little argument to support my view that a manipulated agent of the sort Timmerman envisages does not lead a meaningful life. Having a meaningful life entails the life's having a meaning. This meaning is the content of its narrative. Having a narrative entails free will (the capacity to act freely) insofar as narrativity involves meaning holism. Thus, having a meaningful life requires the capacity to act freely.

\section{Could a Meaningless Life be Worthy of Choice?}

I contend, then, that none of the four lives described by Timmerman is meaningful, but I also believe that the question of whether a life is meaningful is different from the question of whether one would prefer continuing to live it, if given the choice. I might choose to continue a life that contains pleasant experiences (and not too much suffering), because (literally) that's better than nothing. One could conflate the two questions and thus have mistaken views about the meaningfulness of the lives in question.

Everyone in the contemporary debate evaluates Williams's thought-experiment pertaining to Elina Makropulos with the assumption that a meaningless life would not be worthy of choice, and the focus then is on whether the projects would inevitably fade away eventually. This seems to me to over-simplify. If our projects give meaning to our lives, then a life without such projects would be meaningless; but it could still contain pleasures and positive experiences, as an animal's life can.

From the fact that a life would not contain compelling projects, it would not follow that the pleasurable experiences would be desultory and unorganized. An animal recognizes its master and other animals, possibly developing strong feelings of attachment. Animals grieve when they suffer losses. They have a framework within which they organize their experiences - a kind of affective filing cabinet — even though they do not freely choose projects for the future. The same can be true of a human being. A human being could enjoy life, even if not as robustly as possible, without compelling projects.

I think that I would choose such a life, rather than death, and that this decision is defensible. Of course, it would be much better to have a meaningful immortal life, but we are here assuming (for the sake of discussion) that this is impossible. We shouldn't let the perfect spoil the good (or at least, the not so bad)! We should not conclude straightaway that a life is not worthy of choice, if it does not contain projects that would make it a meaningful life. Deliberation is about choosing better and avoiding worse. We play the cards that are dealt us.

Presumably you could have some very pleasant experiences (enjoying a fine meal or piece of music or...) that are not part of ongoing, freely chosen projects. If I were given the choice of an immortal life with such pleasures (but not projects of the relevant kind), or no life at all (i.e., immediate and painless annihilation), I would choose the life. A meaningless life might be worthy of choice, given bad enough options. It is at least not obvious that human beings in general would prefer no consciousness at all ever again to continued conscious life under at least minimally favorable circumstances, even without projects. 
Granted: boredom can become so extreme and disturbing that one cannot enjoy anything, or even be mildly amused by the passing parade of life. Such a life would not be worthy of choice. I am simply observing that the meaninglessness that results from the permanent lack of engaging projects does not in itself entail that one would not prefer continued life, all things considered. Only the death of a creature with the capacity to lead a meaningful life can be tragic for the deceased, but the death of a non-human animal can be bad for the animal. The death of a human being whose life is not meaningful can similarly be bad for the individual, and it would not necessarily be unreasonable to choose to avoid it (given the opportunity).

Consider this hypothetical choice - a science fiction scenario, to be sure, and one not to the liking of Williams and philosophers similarly inclined toward skepticism about wildly implausible thought-experiments. But here goes anyway. You are given this choice: either you will die immediately (and painlessly), or you will be reincarnated as an animal who lives an on-balance pleasant life. (I think of any one of my very pampered cats. I confess that I have on occasion looked at the possibility of "changing places" with them favorably, so far as I could imagine it!). Of course, the coherence of my becoming a nonhuman animal is questionable, but putting this worry aside, I would choose to "continue" life as the animal. Again, I might think: "It's better than nothing."

Putting aside the methodological worries about considering such a hypothetical example, Williams would point out that such story is not of a recognizably human individual. Right, but if one concedes the coherence of the story, one would have to hold that the "recognizably human" constraint is too strong. It should be replaced by the requirement that the life of the envisaged individual be recognizably that of a person (me). I do not however wish to place much weight on this thought-experiment, and I can for the sake of this discussion stick with the "recognizably human" requirement.

\section{Should We Fear Death?}

Summarizing his friendly critique of my views, and stating his, Timmerman writes:

If I am right, death is not something that merits fear since it is not intrinsically bad. Nevertheless, one may rationally fear that they will die within any given timeframe, so long as they're not certain they'll die within that timeframe. Moreover, others may rationally fear the pain that one's death will cause them. Of course, the person who faces death may have all sorts of warranted negative attitudes toward death (or lament death, generally) even if they cannot rationally fear death itself. These considerations hopefully mitigate the counterintuitive cost of accepting my view.

In the book I claimed that it is rational to fear death - not merely premature death, but death itself (conceived as nothingness) — at least somewhat, although not as much as people typically do. Since I wrote the book, I have grown less confident about this position, and I am inclined to agree with Timmerman's convincing arguments. I now accept (for reasons he nicely develops and others) that it is irrational to fear the status of being dead. It may be appropriate to fear that I will die prematurely, but this is 
different from my fearing the status of being dead itself. As Timmerman points out, failure to distinguish "fearing that" from "fear of" can lead one to think that it can be reasonable (or at least not inappropriate) to fear being dead. It doesn't however seem to me appropriate to fear something that does not involve any negative experiences, even if the thing in question is bad for one.

Someone might object by offering the following case, suggested (in correspondence) by Justin Capes:

A doctor tells you there's a $60 \%$ chance your beloved child will die, but if she does you'll be given (whether you want it or not and before you are informed of the child's passing) an elixir that will make it so that the child's death isn't emotionally painful for you (e.g., by causing you not to care, and so forth).

Apparently, you would still fear your child's (premature) death, even though no pain will be present for you. Here again it is important to distinguish "fear of" and "fear that." You could certainly fear that your child will die, but I maintain that it would be inappropriate to attribute to you a fear of your child's death.

Same with the subject in the betrayal-behind-your-back case. It may make sense for such a person to judge that it would be bad and fear that it might happen in the future, even assuming she knows that she will not suffer as a result of it. But this is "fear that," and not "fear of." Fearing that is a kind of judgement, not an emotional/ affective state. "I fear that my friend will be late in picking me up at the airport" is "I'm concerned that my friend will be late in picking me up at the airport." Our terror management strategies address our fear of death, not our judgments or concerns about it.

I wrote in the book that the unknown can be scary. Fair point, but this is because we presuppose that we will be around to experience whatever circumstances ensue. It is frightening to face an unknown future that might involve suffering. By hypothesis we will not, however, be around during the time when we are dead. We will have made a transition into nothingness. We know exactly what nothingness is, and what it feels like: nothing. The point is not that you are still "there" and have some sort of experience of nothingness, like some sort of existentialist hero. To think this way would be to commit the error that Lucretius warned against: illicitly thinking of ourselves as "still there" when we are dead. Rather, you are not around anymore and thus have no experience at all. Julian Barnes writes, "We have NOTHING to be frightened of." (Barnes 2008: 99) I disagree. NOTHING is nothing to be frightened of.

What then is the appropriate attitude toward one's eventual death? If fear is irrational, should we orient ourselves toward death with complete equanimity, as the Epicureans argue? Not quite, unfortunately. As Timmerman points out, even if fear is only rationally targeted to experiential bads, it would seem that we could still have other negative attitudes toward the status of being dead. Would it be progress in the Epicurean project of philosophical therapy to switch our attitude toward death from fear to some other negative attitude or cluster of attitudes? One would not have achieved the desired total serenity, and the answer might depend on the nature and role of the other attitude(s) in the affective ecosphere. Fear can paralyze or otherwise throw us off course, significantly impairing our practical reasoning. Other negative attitudes 
may not have these results (to the same extent), but all negative psychological states carry the risk at least of distraction and can propel unhealthy rumination.

The question of the correct attitude (or perhaps range of such attitudes) toward death is deep and difficult. James Baillie argues that our actual attitude toward death, when we really recognize, in a distinctive way, that we will die, is "existential shock." (Baillie 2020) Sometimes Baillie employs the notion of "existential terror." We all believe that at some point in the future we will die; but when this belief becomes salient in a particular way (it comes alive, to use what might be the wrong adjective!), we change profoundly. Baillie argues that this new way of believing in my future death issues in a revelation that all along my conception of myself as an objectively existing, substantial self was incorrect. I thus am filled with existential terror.

Is this terror an extreme form of fear? I don't believe that Baillie conceives of it this way. It is not so much an attitude based on anticipation, but, rather, revelation. Death itself - future nonexistence - is not what is troubling, on this view; what death shows us about reality and our place in it is disorienting.

Baillie's exploration of these issues helps to exhibit the complexity and profundity of our attitude toward death. We can agree with the Epicureans that the appropriate attitude is not fear, but we have not yet reached the ultimate goal of Epicurean therapy. Really confronting death, we become unmoored from our existential safe harbors and disengaged from our ordinary conceptions of ourselves and our everyday lives. It is an extreme disruption of our metaphysical proprioception. Even if we can avoid the affective distortions caused by fear, or the depressing ruminations stemming from (say) dread, this existential discombobulation may be even more threatening to rationality. The existential shock might distort and even disengage our practical reasoning, at least temporarily.

It is not however clear that this disorientation must be long-lasting and insuperable. It can shake us to the core, but we can right ourselves and regain our psychological balance by various means. Philosophical accounts that "downgrade" the status of the person help us to re-orient ourselves to our future deaths - the genuine recognition of our impending death simply reveals a reality that we can apprehend through philosophical reflection. Buddhist (and other) meditative practices can calm us in our awareness of death. What comes as an unwelcome shock in our lives can sometimes be accommodated eventually, like chronic pain becomes an old friend.

\section{The Lucretian Mirror Image Argument}

Timmerman raises some worries about the Parfit-type response and its philosophical incarnation as the Brueckner/Fischer approach. He writes:

... I'm not sure why the fact that some beliefs or attitudes are conducive to survival is any reason to think that they're rationally justifiable. In fact, some might draw the opposite conclusion. The fact that some belief or attitude is conducive to our survival provides a causal explanation for why we have it and, if our survival doesn't depend on the belief in question being true, then it looks like the cause of our belief isn't connected to its truth in any way. As such, learning of the cause of our beliefs might serve to undermine our justification 
in them. Metaethicists such as Richard Joyce and Sharon Street have taken this as undermining our justification for thinking our moral beliefs are (objectively) true.

Analogously, suppose it's conducive to our survival to be temporally biased. It may be conducive to our survival to be temporally biased whether or not such attitudes are rational, and regardless of whether such beliefs about the value of temporal goods are true. As such, we'd have our temporally biased beliefs selected for whether or not they were true, and this seems like it could be a defeater for such beliefs.

Timmerman's thoughtful critique of the Brueckner/Fischer answer to Lucretius's argument raises many questions, which I cannot fully address here. Here I can only offer some preliminary thoughts. Let us start by considering the argument as it relates to attitudes, rather than beliefs; as Timmerman concedes, this is the primary concern of the Epicureans. The Brueckner/Fischer argument is about having attitudes, not the attitudes themselves. (This is a distinction Timmerman recognizes.) We contend that it is rationally justifiable to have a temporal bias: to care more about future pleasures than past ones. Thus our attitudes toward past and future experiential blanks are appropriately different; it is rational to have a negative attitude toward the future deprivation, but to be indifferent to the past one, all other things equal (a phrase admittedly tricky to spell out).

Our approach contends that it is prudentially better to be affectively oriented toward the future, and thus it is rational to be so oriented, insofar as prudence is a form of rationality. So having at least some negative attitude toward death would be rational, whereas having regret about late birth would not be. The issue of the rationality of the attitudes themselves, rather than the having of them, does not necessarily come up, if it makes sense at all. (In my discussions of the rationality of attitudes, and in particular my discussions above, the assumption is that we are discussing the rationality of the having of attitudes.)

Finally, even if one holds that fear can only be targeted at experiential bads, this does not cut against the basic thrust of the Brueckner/Fischer strategy. The strategy would still imply an asymmetry with respect to having a negative affect toward death, however we characterize it. Timmerman's critique does however force a reconsideration and sharpening of the Brueckner/Fischer approach, which we typically frame in terms of the specific negative affect of fear. It is helpful to distinguish fear from a range of other negative attitudes in thinking about these issues.

\section{Reply to Gorman}

\section{Immortality and Motivation}

Along with others who have written about these issues, Gorman wonders why immortal people would be motivated to act in a timely way. The problem is particularly pressing for truly, and not merely medically, immortal folks, but it is also a challenge for the medically immortal. (Recall that medically immortal individuals are immune 
to aging and death from natural causes, but not from death by any cause. Medical immortality has been estimated currently at about 6000 years.) They illustrate the worry nicely with this little conversation (no doubt, one of many between these two tortured characters - maybe infinitely many!):

IMMORTAL LOVER 1: All I'm asking you to do is to commit to being with me for the rest of time.

IMMORTAL LOVER 2: I fully intend to commit to you, but I just don't understand why you're rushing me and I can't spend 2,000 years doing something else first.

IMMORTAL LOVER 1: Call me greedy if you want, or just head-over-heels in love, but I want as long of a period of time to spend with you as possible!

IMMORTAL LOVER 2: How many times do I have to tell you? Whether I commit to you now, one year from now, or 2,000 years from now, we will have the exact same amount of time to spend together: No years!

IMMORTAL LOVER 1: I feel like every 2,000 years when I ask for your commitment you always say the same thing...

Many worry that immortality weaponizes procrastination. Why bother? There will always be time (especially assuming true immortality). Although the issues are complex, I think that the general worry about motivation and timely action fails to recognize an important fact about us: the importance of "now," or less elegantly, the importance of the temporally proximal. We live in the present, and we strongly prefer that current bads, especially experiential bads, be eliminated as quickly as possible, and prospective goods be enjoyed as soon as possible (other things equal). We do not just wish to maximize total time together, no matter how it is distributed, and, specifically, we would be extremely disappointed with an avoidable wait of 2000 years for the many and tremendous goods of love. Not only would we be disappointed, but it would be very disturbing to know that a putative lover would not mind - or even would prefer-such a delay.

LOVER 1 would justifiably feel that LOVER 2 is not really a "lover," at least of them. A genuine lover would not spend 2000 years dabbling in other projects and experimenting with other people. It is one thing to sow your wild oats, getting them out of your system; but does this apply even after a loving relationship is established? How long does it take? The dialogue presents the two as at least putative or "wannabe" lovers, but one who still needs to sow those oats for thousands of years is not yet a lover. One of the inescapable, and sometimes devastating, characteristics of romantic love is the strong desire to be with the loved one now-a point made by Aristotle in his discussion of "friendship." This is why LOVER 1 would be so disappointed, and not just because they have been put off before.

In general, immortal life would be no different from our mortal lives with respect to the importance of now (and the temporally proximal). Suppose as an immortal you are in terrible pain from an accident. Pain would certainly be present in immortality. If a member of an emergency medical team on the scene says, "Don't worry. We won't give you the shot of morphine, because eventually you won't be in pain. In either scenario - the morphine-now scenario or the no-morphine-now scenario-you will live the same number of pain-free years, so why bother?" Surely, you are likely 
to say, "It DOES matter, because I hurt now. I want it to go away as soon as possible, and the point about the total number of pain-free years is quite beside the point. Give me the shot!"

There are many constraints on our tendencies toward sloth and procrastination, although perhaps not as many as would be ideal. In an immortal life, I could be in pain or suffering in other ways - from anxiety, depression, loneliness, boredom, or a myriad of other lamentable conditions. I will want to take action to prevent the onset of them. If I am now suffering, I will want to take action to alleviate the suffering as soon as possible. If the enjoyment of a good, or the elimination of a bad, has to be delayed, then I must deal with the situation with patience; this is true in our mortal lives, and it would be equally so in an immortal life. What is problematic, in either sort of life, are unnecessary delays. Death is not the only thing that motivates us.

Some wonder what would get us to get off the existential couch in an immortal life. It is just possible that such fortunate people might never have been in love with a partner from whom they have been separated or have been at least temporarily prevented from pursuing their most compelling projects by injuries, illnesses, financial hardships, and so forth. Our experiences are in the now, and, wired as we are, we care especially about the temporally proximal. Presumably this would not change if we were to stretch out our lives temporally. It is, you might say, the temporal logic of human experience.

Justin Capes has helpfully reminded me of young people who "think they are immortal." When we're young we don't take our mortality seriously — it is not "real" to many young people and thus doesn't structure much of their motivation. And yet they still pursue projects. They do this because they want a better future or more money or prestige, and they want these things sooner rather than later. Again: the possibility of death is not the sole motivation for human beings.

\section{Recognizability and Narrativity}

Gorman thinks that there is a tension between my acceptance of the possible recognizability of an immortal human life and my claim that our lives are narratives, strictly construed. Narratives have endings, and they engender a particular kind of understanding: a "totalizing" explanation, which interprets the parts through the lens of the whole, and, in particular, the ending. Truly immortal lives have no endings, and thus their stories are not narratives, or so it might seem. They write:

I take it that an important part of writing the stories of our lives is aiming to end up with the kind of life that we would be most satisfied with, if we were to look back at the end of it all, and for many of us a relevant feature to our degree of satisfaction is the narrative that holds all of the events together.

This is an intriguing point that raises difficult questions. My views about practical reasoning and satisfaction with one's life are somewhat different from my views about narrativity and meaningfulness. On my view, when we act freely, we write a sentence in the narrative of our lives. In virtue of being a narrative, the story has meaning holism. It does not, however, follow, and I do not hold that, in our practical 
reasoning we need to be guided by the goal of making our narratives more cohesive or "better stories" in an aesthetic sense of interest to a reader or literary critic.

I do not share the view that in our practical reasoning, an important goal is to "end up with the kind of life that we would be most satisfied with..." This certainly is not the way we explicitly deliberate, and I doubt whether we implicitly think this way in our practical reasoning. Ought we to? I'm not sure why, and more would need to be said about what kind of coherence is demanded, if our lives are to be viewed as satisfying from the perspective of the ending.

Our lives are messy - this is a central tenet of postmodernism (and despite this, it is true!). We have complicated personal relationships and often (especially these days) need to change jobs or even careers, and so forth. Is a life with only one job throughout one's working life, or one career, necessarily more satisfying than a life with various jobs or careers? Some get married four or five times. This is a recognizably human story, but looking back on it, would it necessarily be deemed unsatisfactory or less worthy than a life with only one marriage (or job) that lasts a long time?

There are two separate points here. One: do we have as a goal in practical reasoning a positive judgment from the perspective of the end of our lives? Two: is greater cohesiveness one of the main elements of such a judgment? At best I think these indicate considerations that may be desiderata, all other things equal, but are not necessarily decisive.

Psychologists emphasize the importance of endings. This point is specifically about periods of one's life, and it is warranted in part because our memories will be more agreeable as we go forward, if the endings go well. We are psychologically attuned to endings, because a good ending can help us achieve closure and move on with our lives in happier, more productive ways. This insight however does not generalize to the end of a life as a whole.

I have no doubt that some immortal lives would not be recognizable as narratives. For example, Gorman writes:

But without any fixity of how significant a particular period of time or episode is going to be in the grand scheme of one's life, one could decide last minute to take a two-hundred year project, zoom out their perspective on the life-narrative, and treat it as merely a footnote. This seems to me to be significantly different from the way in which our finite self-narratives affect our choices.

My point, however, is that we can conceive of some stories of immortal lives as narratives. Immortality, even true immortality, does not in itself entail the impossibility of narrativity. Immortality curmudgeons such as Williams (and his followers) contend that no immortal life could be recognizably human, or if recognizably human, worthy of choice. In contrast I do not believe that an immortal life would be necessarily unrecognizable as human, or necessarily unworthy of choice.

\section{Would Immortal Life Necessarily Be Boring?}

Gorman dives into the deep waters of the boredom issue with a thoughtful and probing discussion, focusing on a debate between Shelly Kagan, and Philip Bricker and me. (Kagan 2012, Bricker 2020) They ask difficult questions, not content to float at 
the surface, as I'm afraid I was in the book. A problem is that it is extremely difficult to articulate what is valuable about an experience, and I appreciate the invitation to think about it more here. I wrote in the book that it may be that Shelly Kagan focuses on an extractable cognitive ingredient - an insight or new information gained from the experiences. When no new insights are forthcoming over time, he would have "got all there is" from this kind of experience. I wanted to insist that many kinds of experiences are compelling, but not in virtue of an extractable cognitive component.

The relevant sort of feature of valuable experience may be ineffable, but I don't think that its ineffability is what makes the experiences repeatably compelling (in immortality). Neither ineffability nor unpredictability fully explains the phenomenon of reliably compelling repeatability of experiences valued for their intrinsic features. The experiences under discussion may be "particular," in some sense, but I don't believe that their particularity is what makes them repeatably compelling. Further, I could imagine being able to characterize a kind of non-extractable, intrinsic feature of an experience that makes it repeatably compelling. That kind of experience may be repeatably compelling, even if I can predict in advance that it will accompany a certain activity. But can we say more about what the "kind" in question is, and why it can underwrite reliably repeatable engagement?

Kagan contends that nothing, including the allure of Thai food, can propel us into the infinite future. He loves Thai food, but contends that it would become boring after awhile, if that were one's only kind of food:

Instead of Thai [food] every day for all eternity, perhaps it could be Thai for lunch on Mondays, Wednesdays, and Fridays, with Italian for lunch on Tuesdays and Thursdays, and Ethiopian for dinner on Saturday night, and so forth and so on. Perhaps we could spend three hours in the morning doing philosophy, and then two hours in the afternoon doing math, and then spend the evening watching a movie or going to the theater. I must say, that sounds like a pretty pleasant life. But it doesn't really help. Because, again, when I think of doing this, not just for years, or decades, or even centuries, but for all eternity, never getting away from it, never being free from it, it all turns sour. The seemingly positive dream of immortality becomes a nightmare, a nightmare from which we can never escape. (Kagan 2012: 243)

Contrast this with a passage from Philip Bricker:

There are countless greater infinities that dwarf aleph-null as surely as alephnull dwarfs our customarily allotted three score and ten. Why settle for a piddling aleph-null years ...? What point could there be to living [more than aleph-null years]? ... [A plausible answer] gives reason for wanting to live for any number of years, no matter how large the number. It begins by noting that there are pleasures [repeatable pleasures] that we never grow tired of, of which we can say: 'the more, the better.' Take, for example, my unflagging desire for Thai food: I want to eat it this week, and the week after, and so on... (Bricker 2020: 315, 321).

I wish I could say more about what makes an experience repeatably compelling or what explains the debate between folks like Kagan and Bricker (and me). I believe 
that all of us agree that the factor in question is not (solely or primarily) that the experiences contain pleasure or produce it as a byproduct. That would be reductionistic in an unattractive way, except if one accepts hedonism about intrinsic value. Accepting this hedonistic view however doesn't help much, since it is essentially contentious whether such pleasures would inevitably run out. Bricker and I do not believe they necessarily would.

Could it be that Thai food or food in general just tastes better to Bricker and me than Kagan? I doubt it, and there's no way to tell! Could it be just a matter of different personalities? In her insightful paper on Williams's analysis of Elina Makropulos, Rosati suggests this sort of explanation:

Perhaps the moral, then, [of Williams's discussion] is not that extended existence would be undesirable simply because of what it is to have a human character and live a human life, but that it would be undesirable for those whose circumstances will be seriously impoverished or for those who have, as a matter of individual characters, both limited interests and a tendency to become easily and intolerably bored. (Rosati 2013: 335-336)

I commend a change in our orientation to the activities and projects of our lives: we shouldn't ask how we can get more out of our activities, but how we can get more into them. This represents a fundamentally different way of thinking of value in life. When we act mindfully, we are immersed in our actions with a full appreciation of what we are doing and its context. We value acting in a certain way - mindfully — but not because of pleasure or pleasant experience that is a byproduct of it. We are "into" it.

Why can't we continue to find such spiritual experiences compelling in an immortal life? Why couldn't they propel us into the future, especially when combined with a smorgasbord of pleasures? Whatever the answers to these fundamental questions turn out to be, I appreciate Gorman's more precise articulation of the points at issue, and their invitation to think more deeply about them.

\section{Do NDEs Give Us Reason to Accept Supernaturalism?}

Gorman raises the question of the epistemic status of near-death experiences (NDEs). They ask:

I can see why people who have Near-Death Experiences would be averse to hearing that they have no good reasons to believe that they aren't something much more akin to dreams. Given that they are experienced as being more real than ordinary reality and they occur when one is near death, is [it] really that unreasonable to think that a good explanation is that there is some realm after death?

Fischer thinks it is unreasonable.

Upon more careful reflection, spurred in part by Gorman's discussion, I'm not exactly sure what to think about the probative relevance of NDEs, and I agree that their evidentiary import deserves further exploration-more than I can give here. I simply wish to assemble some preliminary thoughts. 
I agree with the thrust of Gorman's remarks, and the way I would put it is that NDEs are a species of spiritual experience, and specifically, mystical experience. NDEs take place in near-death contexts, whereas mystical experiences need not, but they have all the main characteristics of mystical experiences: a direct "perception" or "sensing" of a divine presence, at least part of which typically is ineffable, the overwhelming sense of the "reality" or veridicality of what is sensed (what William James called the "noetic quality" of mystical experience [James 1936]), a feeling of peace and bliss, and a recognition of the "unity" of fundamental reality (and thus the disappearance of the substantial self as a separate entity). All these are featured prominently in NDE reports. For example, Eben Alexander expresses the noetic quality of his NDE by calling it "ultra-real." (Alexander 2012).

Do mystical religious experiences (a sub-species of mystical experiences) give the individual who has them good or perhaps decisive reason to accept their veracity and thus to believe in the divine entity presented? This is highly contentious. Some thoughtful people do indeed accept that such experiences give the individual having them good, and perhaps even sufficient, reason to accept their veracity. As Gorman notes, however, it would not follow from the fact that some report having these experiences that they give the rest of $u s$ (who have not had mystical religious experiences) such reasons. In his famous treatment of these issues, William James holds that whereas mystical religious experiences give the experiencer decisive reasons to accept their veracity, they do not give others such reasons. (James 1936)

I am frankly skeptical about whether NDEs give the NDEr any reason to believe in their veracity (in the sense of representing contact with a supernatural realm via a non-physical mind), given that there are other, very plausible naturalistic explanations of NDEs. Then there is the annoying problem that the specific contents of NDEs often paint incompatible pictures of the afterlife.

Let's however stipulate that NDEs give NDErs pro tanto reason to believe in a guided journey through a supernatural realm (an actual journey of this sort, not just an experience as if one is having one). It does not follow that they generate strong, or certainly not all-things-considered, reasons for the NDEr to believe this. Further I agree with James's point that these sorts of experiences do not give non-NDErs (third parties) even pro tanto reasons. It is in the nature of mystical experiences that their probative force cannot be represented or acknowledged from a third-person point of view; their evidentiary status is essentially first-personal.

Gorman writes:

Of course I see the appeal of the naturalistic project and the hope of being able to get everything to fit within its paradigm, but I think Fischer's faith in science here might be a bit inflated. Even if we were able to identify some physical processes, there would remain a question of whether or not they provide the whole story, as it were.

My faith in science might well be inflated, but not because I think that physical processes will "provide the whole story." I don't. As a naturalist, and a materialist about the mind, I believe that experiences are indeed physical processes. I am not a "typetype" materialist, but some sort of "token-token" materialist, broadly construed. That is, I do not believe that we can identify types of physical processes that correlate 
with types of experiences, especially with types of contents of experiential states. I do however believe that every experience is either identical to or constituted by a particular physical process; perhaps more precisely, the experiences supervene on the physical processes.

I also contend, however, that the cognitive contents of the mental states and our articulations of the "raw" phenomenology are deeply conditioned by our social circumstances and cultures. A Japanese NDEr may see a flash of light and not attend to it or give it any significance, whereas a Western NDEr may interpret it as a light at the end of a dark tunnel. In Japan there's a trope to the effect that it is desirable to tend a rock garden with loved ones as one gets older, and we in the West hold that there's always light at the end of the tunnel. Our cultural backgrounds affect our phenomenology - how we construct the meaning of the raw data of experience. Japanese NDErs may see rock gardens.

In general, I maintain that the mental supervenes on the physical. This is a metaphysical point. I am not however a reductionist or eliminativist about the mental, because I believe that mental content and explanations of our experiences and actions are often not most helpfully framed in physical vocabulary.

The whole story of NDEs, if it is ever told, will be multifaceted, and, as with other mental phenomena, will advert to a complex interrelationship between the biological/ physical and the social/cultural. I believe that fundamental reality is indeed physical: what exists, at a basic level, is given by what is invoked in the best science (perhaps, although not necessarily, physics), and everything else supervenes on the basic features of reality. Scientific explanations, however, especially explanations in terms of a physical vocabulary, are not always the most useful or illuminating; sometimes we need, or find most useful, explanations that invoke mental content and social phenomena. In this sense physical processes do not provide the whole story. They key here is to distinguish the metaphysical and explanatory contexts.

Alternatively, one might find the key in distinguishing what NDEs are, from their meanings (or interpretations). In my view, NDEs are physical phenomena in our brains. Their meanings are the stories they tell of journeys from the known to the unknown, guided by loving mentors, in search of connections of objective value. Such stories engage with our emotions in a deep way, based on our experiences of such voyages of discovery throughout the various parts of our lives. This is an important reason why they are so profoundly transformative.

Open Access This article is licensed under a Creative Commons Attribution 4.0 International License, which permits use, sharing, adaptation, distribution and reproduction in any medium or format, as long as you give appropriate credit to the original author(s) and the source, provide a link to the Creative Commons licence, and indicate if changes were made. The images or other third party material in this article are included in the article's Creative Commons licence, unless indicated otherwise in a credit line to the material. If material is not included in the article's Creative Commons licence and your intended use is not permitted by statutory regulation or exceeds the permitted use, you will need to obtain permission directly from the copyright holder. To view a copy of this licence, visit http:// creativecommons.org/licenses/by/4.0/. 


\section{References}

Alexander, Eben, M. D. 2012. Proof of heaven: A neurosurgeon's journey into the afterlife. New York: Simon and Schuster Paperbacks.

Baillie, James. 2020. The recognition of nothingness. Philosophical Studies 177(9): 2585-2603.

Barnes, Julian. 2008. Nothing to be frightened of. New York: Knopf.

Bradley, Ben, Fred Feldman, and Jens Johansson, eds. 2013. The oxford handbook on the philosophy of death. New York: Oxford University Press.

Bricker, Phillip. 2020. On living forever. In Modal matters: Essays in metaphysics, 315-326. New York: Oxford University Press.

Chalmers, David. 2022 (forthcoming). Reality +: Virtual worlds and the problems of philosophy. New York: W.W. Norton and Company.

James, William. 1936. The varieties of religious experience. New York: The Modern Library.

Kagan, Shelly. 2012. Death. New Haven: Yale University Press.

Nozick, Robert. 1974. Anarchy, state, and utopia. New York: Basic Books.

Rosati, Connie S. 2013. The Makropulos case: reflections on the tedium of immortality and agency. In eds. Bradley, Ben, Fred Feldman, and Jens Johansson 2013: 355-390.

Velleman, D. 1991. Well-being and time. Pacific Philosophical Quarterly 72(1): 48-77.

Publisher's Note Springer Nature remains neutral with regard to jurisdictional claims in published maps and institutional affiliations. 